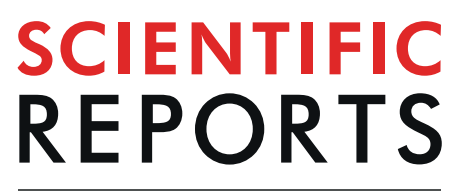

natureresearch

\title{
OPEN Organic bases catalyze the synthesis of urea from ammonium salts derived from recovered environmental ammonia
}

\author{
Yuichi Manaka $\mathbb{1}^{1,2^{*}}$, Yuki Nagatsuka $^{1} \&$ Ken Motokura ${ }^{1}$ \\ Ammonia from sewage and livestock manure is a major environmental pollutant. To consume \\ environmental ammonia, we investigated the organic base-catalyzed synthesis of urea. \\ 1,8-Diazabicyclo[5.4.0] undec-7-ene (DBU) catalyzes the conversion of ammonium carbamate to urea in \\ $35 \%$ yield at $100^{\circ} \mathrm{C}$. Moreover, DBU also converts other ammonium salts into urea. A mechanism that \\ involves nucleophilic attack of ammonia following ion exchange is proposed.
}

\begin{abstract}
The use of untapped environmental resources with the aim of establishing a sustainable society is attracting increasing attention. Among these resources, sewage and livestock manure have been estimated to contain large amounts of ammonium ions (environmental ammonia) ${ }^{1-9}$. The recovery and use of environmental ammonia represents a possible alternative route to the Haber process for the supply of ammonia. Since environmental ammonia is an environmental pollutant, it is generally decomposed into molecular nitrogen and carbon dioxide at treatment plants with adding of methanol through nitrification and denitrification processes ${ }^{10}$ that involve microorganisms and significant heat energy (Fig. 1). This treatment process also produces $\mathrm{N}_{2} \mathrm{O}$ as a byproduct, which is a well-known greenhouse gas ${ }^{11-14}$. In other words, the treatment of environmental ammonia promotes global warming through the use of additional energy and the production of $\mathrm{CO}_{2}$ and $\mathrm{N}_{2} \mathrm{O}$. Other methods for separating ammonia from wastewater involve ammonia stripping ${ }^{15-17}$ or the use of an ammonia sorbent; ${ }^{18-21}$ while these processes are purposed to remove ammonia, they also require the use of additional bases and heat for operation. In addition, even when ammonia is recovered by ammonia stripping, its purity is low and further purification is required.

If it were possible to recover and reuse environmental ammonia, this unnecessary environmental pollutant becomes a useful chemical resource, which presents a new possible solution for current environmental problems and the supply of an important resource.

Recovering ammonium carbonate, ammonium bicarbonate, or ammonium carbamate by reacting ammonium ions with carbon dioxide (and water) is possibly the least expensive method for recovering environmental ammonia from the perspectives of cost and ammonia condensation. These recovered ammonium salts are not very thermodynamically stable and/or are easily thermally decomposed to ammonia (for reuse as ammonia gas) and carbon dioxide ${ }^{22}$. If the recovered ammonium salts can be directly converted into urea with less additional energy input, which is a more useful industrial chemical product, the usefulness of this ammonia-recovery process is further increased (Fig. 1).

Urea is a well-known chemical product and is a raw material for fertilizer and polymers ${ }^{23-25}$. Urea has also attracted attention as a solid-state energy carrier in recent years ${ }^{26,27}$. Urea is directly synthesized from carbon dioxide and ammonia (from Haber process) commonly ${ }^{28-30}$. The reaction generally operates at $150^{\circ} \mathrm{C}$ and at a pressure of $2 \mathrm{MPa}$, and the urea-synthesis plant can be sustained because of its vicinity to the ammonia-synthesis plant from which it derives much of its input energy ${ }^{31}$. Due to these energy factors, conventional energy-consuming urea synthesis method is not suitable for environmental ammonia usage. On the other hands, since nitrogen in recovered ammonium ion does not have extreme strong triple bond as $\mathrm{N}_{2}$, there is no need additional energy for dividing $\mathrm{N}_{2}$ bond like Haber process and is an advantage compared with conventional urea synthesis method

${ }^{1}$ School of Material and Chemical Technology, Tokyo Institute of Technology, 4259 Nagatsuta-cho, Midori-ku, Yokohama, Kanagawa, 226-8502, Japan. ${ }^{2}$ Renewable Energy Research Center, National Institute of Advanced Industrial Science and Technology, 2-2-9 Machiikedai, Koriyama, Fukushima, 963-0298, Japan. *email: manaka.y.aa@m.titech.ac.jp
\end{abstract}




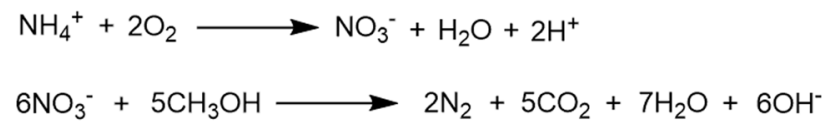

\section{Catalyst}

This Work<smiles>NC(N)=O</smiles>

Ammonium salts

Figure 1. Environmental ammonia treatment methods.

via Haber process. It is crucial for urea synthesis reaction to decrease the input energy to be accepted by society because one of the purposes of environmental ammonia usage is to reduce the ammonia treatment energy.

Urea has also been synthesized from ammonium carbamate as the substrate and a Cu catalyst; ${ }^{32}$ in this report, a $54 \%$ yield of urea was achieved at $140^{\circ} \mathrm{C}, 14 \mathrm{MPa}$, and $3 \mathrm{~d}$ of incubation. However, large amounts of energy are still required for the reaction. In other report, urea has been synthesized from ammonium carbamate and ammonium bicarbonate mixtures as the substrate; $;^{33}$ in this report, a $48.9 \%$ yield of urea was achieved at $165^{\circ} \mathrm{C}$, 3.6 MPa, and $90 \mathrm{~min}$ of incubation. Large amounts of energy for heating and compressing are still required for the reaction. For further input energy decrease, efficient catalyst for ammonium salt conversion into urea is required.

Herein, we report the synthesis of urea from ammonium salts under milder conditions than other methods previous reported. The reaction was achieved by using organic base as a catalyst. This study is the first to investigate ammonium salts conversion to urea in order to consume environmental ammonia using organic base catalyst.

\section{Results}

Catalyst screening. The first urea-synthesis screening experiments were performed with a variety of organic bases as catalysts and ammonium carbamate as a substrate. The urea-synthesis results using these bases in NMP as the solvent are summarized in Fig. 2. It should be noted that ammonium carbamate decomposes to ammonia and $\mathrm{CO}_{2}$ at $59^{\circ} \mathrm{C}$; consequently, some of the ammonium carbamate is converted into these gases in the closed reaction vessel, and the gases increase the inside pressure of the reaction vessel. From Fig. 2, strong bases were observed to catalyze the conversion of ammonium carbamate into urea. No other urea derivative, such as biuret, triuret, or cyanuric acid was detected.

Although a different solvent was used in these experiments, the $\mathrm{p} K_{\mathrm{a}}$ values of the corresponding conjugated acids in $\mathrm{AcCN}^{34,35}$ provide valuable insight; bases with conjugate acids with $\mathrm{p} K_{\mathrm{a}}$ values greater than 20 catalyze the conversion of ammonium carbamate into urea (Entries 1-5, Fig. S1). Among them, 1,8-diazabicyclo[5.4.0] undec-7-ene (DBU) showed especially high activity, providing urea in $18 \%$ yield (Entry 1, Fig. S1). Although the reason for the high activity of DBU is not clear, it is possible that the stability of DBU in the catalytic reaction plays an important role because TMG and DBN decompose in the reaction solution.

Solvent effect on urea synthesis. We next examined the effect of the solvent in the synthesis of urea using the most active DBU catalyst. Figure 3 lists the urea-synthesis results using solvents with $\mathrm{CO}_{2}$ solubility and relative dielectric constant ${ }^{36-39}$. No correlation was observed between $\mathrm{CO}_{2}$ solubility and the yield of urea. On the other hand, the relative dielectric constant of the solvent was observed to correlate with the urea yield. Following these two results, this trend appears to be attributable to the solubility of molecular ammonia in the solvent. The maximum yield of $35 \%$ was achieved at $100^{\circ} \mathrm{C}$ in DMSO as the solvent over a prolonged reaction time (Entry 2, Fig. 3). The solvent without base did not show the efficient catalytic activity (Fig. S2).

Substrate scope. Ammonium carbonate, ammonium bicarbonate, and ammonia gas, which are possible forms of recovered ammonia from the environment, were also employed as substrates for the synthesis of urea in addition to ammonium carbamate, the results of which are shown in Fig. 4. DBU successfully catalyzed the synthesis of urea from the ammonium carbonate despite ammonium carbonate as the substrate generate two water molecules during the reaction (Entries 1, Figs. 4 and S3). Since the generated amount of water is larger than that of the carbamate used as the substrate in the reaction, the equilibrium conversion is lower than that obtained using ammonium carbamate; hence, the lower yield in Entry 1 is attributable to the lower equilibrium conversion. Ammonium bicarbonate also generates more water than ammonium carbamate in this process. Nevertheless, 


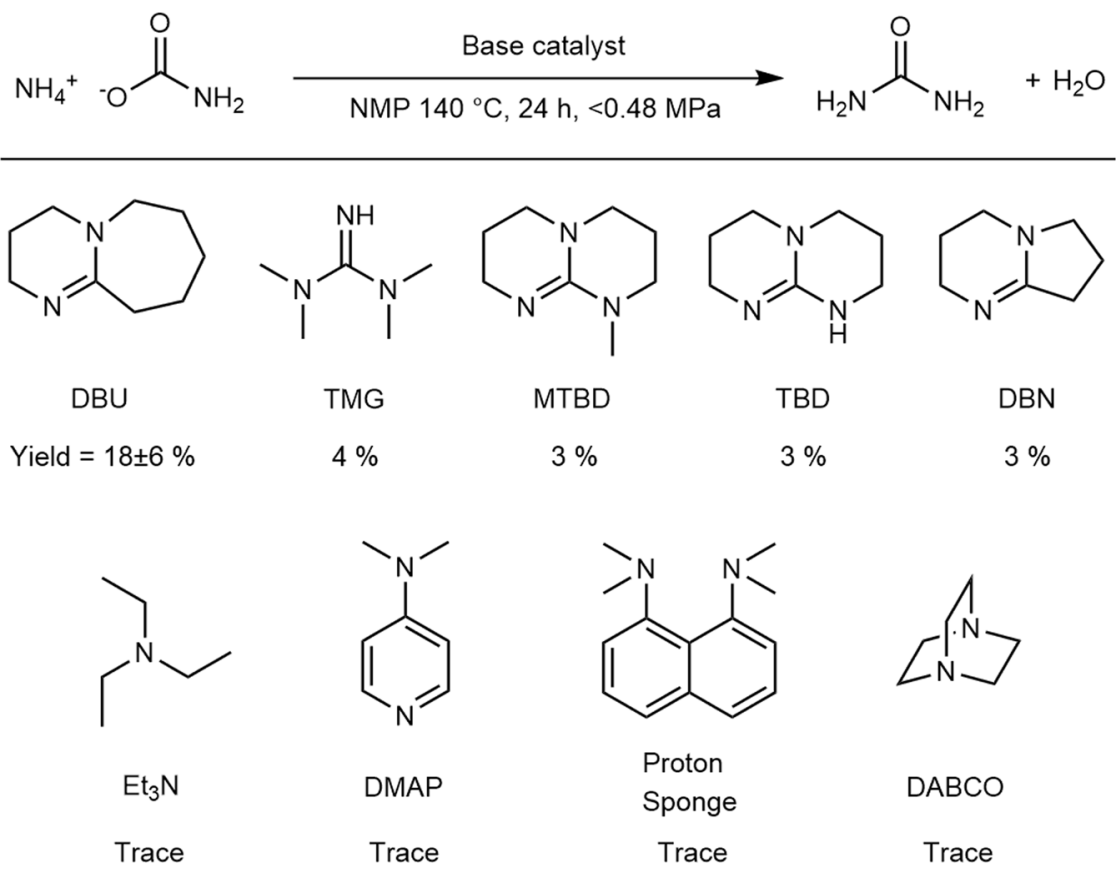

Figure 2. Results of urea synthesis from ammonium carbamate catalyzed by organic base catalysts. Details of the abbreviations used are provided in the experimental section. Experimental conditions: Base ( $0.38 \mathrm{mmol})$, ammonium carbamate $(3.8 \mathrm{mmol}), 140^{\circ} \mathrm{C}, 24 \mathrm{~h}$, in $1 \mathrm{~mL}$ of NMP. Pressure of the inside of the vessel was increased up to $0.48 \mathrm{MPa}$ because of autogenous pressure of thermal decomposition of ammonium carbamate. The amount of produced area was determined by the Fearon reaction (see experimental section).

\begin{tabular}{|c|c|c|c|c|}
\hline Entry & Solvent & $\begin{array}{l}\text { Solubility of } \mathrm{CO}_{2} \\
(\mathrm{~mol} / \mathrm{L})^{36-39}\end{array}$ & $\begin{array}{c}\text { Relative } \\
\text { dielectric } \\
\text { constant }\end{array}$ & Yield (\%) \\
\hline 1 & $\mathrm{H}_{2} \mathrm{O}$ & 0.196 & 80.4 & trace \\
\hline 2 & DMSO & 0.134 & 46.5 & $35 \pm 1$ \\
\hline 3 & $\mathrm{MeCN}$ & 0.282 & 35.9 & 18 \\
\hline 4 & NMP & $N / A$ & 32.2 & 5 \\
\hline 5 & THF & 0.210 & 7.6 & trace \\
\hline 6 & 1,4-dioxane & 0.255 & 2.2 & trace \\
\hline 7 & Toluene & $\mathrm{N} / \mathrm{A}$ & 2.4 & trace \\
\hline
\end{tabular}

Figure 3. Urea synthesis from ammonium carbamate in various solvents. Experimental conditions: DBU $(0.80 \mathrm{mmol})$, ammonium carbamate $(4.0 \mathrm{mmol}), 100^{\circ} \mathrm{C},<0.37 \mathrm{MPa}, 72 \mathrm{~h}$, in $1 \mathrm{~mL}$ of solvent.

DBU also successfully catalyzed the synthesis of urea from the ammonium bicarbonate. Urea can also be synthesized from gaseous substrates. Ammonia and $\mathrm{CO}_{2}$ are the thermal decomposition products of ammonium carbamate, as mentioned above. This result indicates that the decomposition of ammonium carbamate, as the substrate, is likely to play a role through dissolution in the reaction solvent. 


\begin{tabular}{|c|c|c|c|}
\hline Entry & Substrate & $\begin{array}{l}\text { Urea produced } \\
(\mathrm{mmol})\end{array}$ & $\begin{array}{l}\text { Yield of } \\
\text { urea (\%) }\end{array}$ \\
\hline 1 & $\mathrm{NH}_{4}{ }^{+}$ & 0.06 & 2 \\
\hline 2 & Ammonium carbonate & 0.41 & 11 \\
\hline 3 & $2($ Ammonia $)+\mathrm{CO}_{2}{ }^{\mathrm{a}}$ & 0.49 & 13 \\
\hline
\end{tabular}

Figure 4. Urea synthesis from possible forms of recovered ammonia. Experimental conditions: DBU

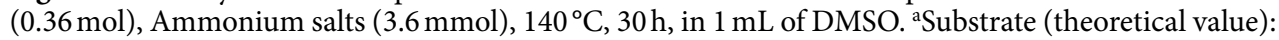
Ammonia gas $(0.72 \mathrm{mmol}), \mathrm{CO}_{2}(0.36 \mathrm{mmol})$. The method used to generate ammonia gas and $\mathrm{CO}_{2}$ gas is described in the ESI, and the reaction schemes are shown in Fig. S3.

(A)

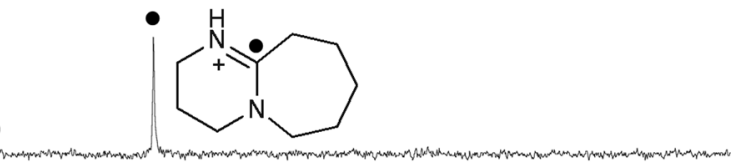

(B)
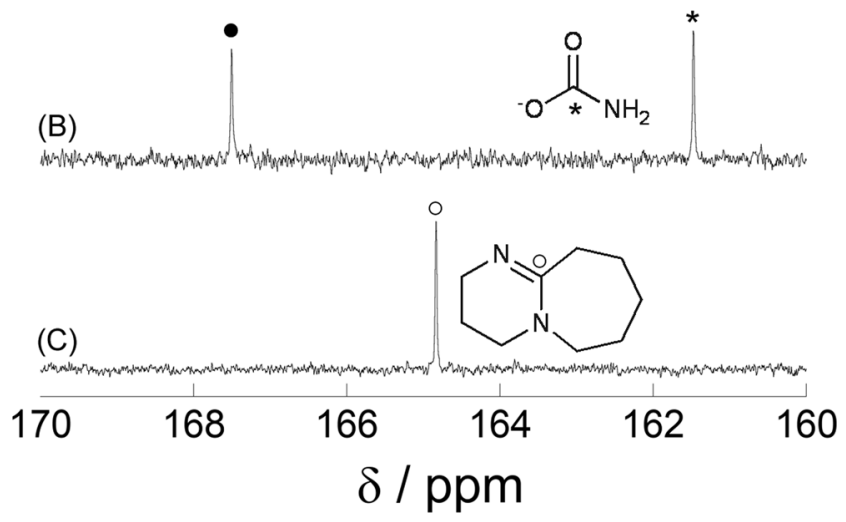

Figure 5. ${ }^{13} \mathrm{C}$ NMR spectra in methanol- $\mathrm{d}_{4}$ of $(\mathbf{A}) \mathrm{DBU}+\mathrm{H}_{2} \mathrm{SO}_{4},(\mathbf{B}) \mathrm{DBU}+$ ammonium carbamate, and (C) DBU. Filled circle: quaternary carbon atom of $\mathrm{DBUH}^{+}$, Open circle: quaternary carbon atom of DBU, Asterisk: carbonyl carbon atom of carbamate anion.

Reaction intermediate measurement. We used ${ }^{13} \mathrm{C}$ NMR and FT-IR spectroscopies to investigate the reaction mechanism involved in the synthesis of urea catalyzed by DBU; the ${ }^{13} \mathrm{C}$ NMR spectra are displayed in Fig. 5. As shown in Fig. 5C, the signal of the quaternary carbon in DBU is observed at around 165 ppm. This signal was observed to shift downfield to $167 \mathrm{ppm}$ when ammonium carbamate and DBU were mixed (Fig. 5B). On the other hand, the spectrum of DBU mixed with sulfuric acid (Fig. 5A) showed the same chemical shift as the DBU + ammonium carbamate mixture. Since DBU protonated by sulfuric acid (Fig. 5A) showed the same chemical shift as the DBU with ammonium carbamate, we conclude that the signal observed by mixing DBU with ammonium carbamate is due to protonated DBU, which is also consistent with the shift behavior of protonated $\mathrm{DBU}$ in a literature report ${ }^{40}$. On the basis of these results, cation exchange seems to have proceeds to form the DBU salt ${ }^{41}$ of carbamic acid and ammonia. When $\mathrm{Et}_{3} \mathrm{~N}$, which does not produce urea from ammonium carbamate, was employed as the base, this shift phenomenon was not observed (Fig. S4). We have identified that the cation-exchange reaction is important for the efficient synthesis of urea.

The FT-IR spectra of DBU, ammonium carbamate, and a mixture of DBU and ammonium carbamate are shown in Fig. $6 \mathrm{~A}-\mathrm{C}$, respectively. A peak assignable to the $\mathrm{C}=\mathrm{O}$ stretch is observed at around $1628 \mathrm{~cm}^{-1}$ in the spectrum of ammonium carbamate. On the other hand, when ammonium carbamate and DBU were mixed, this $\mathrm{C}=\mathrm{O}$ stretch was observed to shift from $1628 \mathrm{~cm}^{-1}$ to $1589 \mathrm{~cm}^{-1}$, which is a $40 \mathrm{~cm}^{-1}$ shift to lower wavenumber; no such shift was observed when $\mathrm{Et}_{3} \mathrm{~N}$ was used (Fig. S5). We conclude that a base that is unable to participate in cation exchange is unable to activate the $\mathrm{C}=\mathrm{O}_{\text {group }}{ }^{42}$.

Figure 7 shows the Arrhenius plot of the logarithm of the initial urea synthesis rate constant as a function of reciprocal reaction temperature. The initial urea synthesis rate was determined by time-dependence experiments (Figs. S6 and S7) and was observed to increase with increasing reaction temperature. The apparent activation 


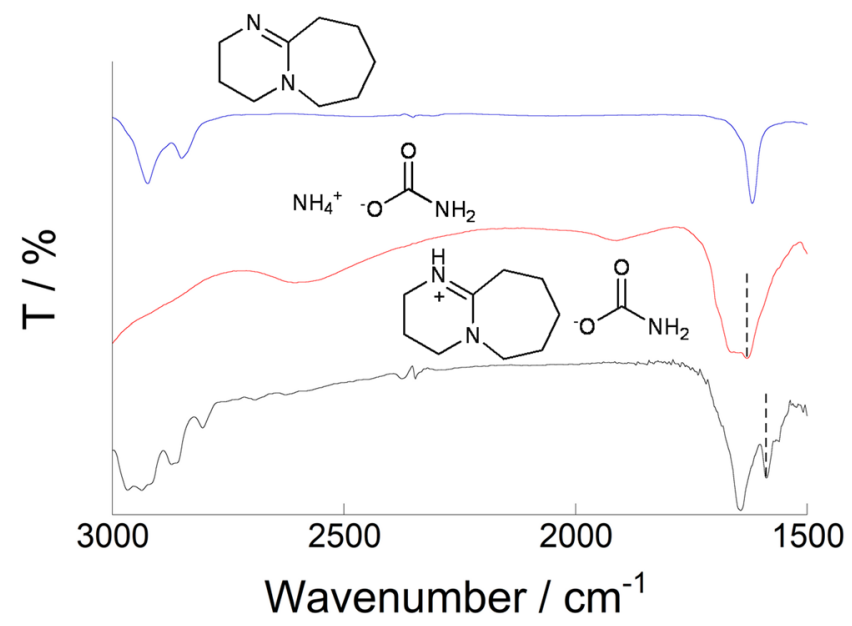

Figure 6. FT-IR spectra of (A) DBU, (B) ammonium carbamate, and (C) DBU + ammonium carbamate. Dashed line: $\mathrm{C}=\mathrm{O}$ stretch of carbamate anion.

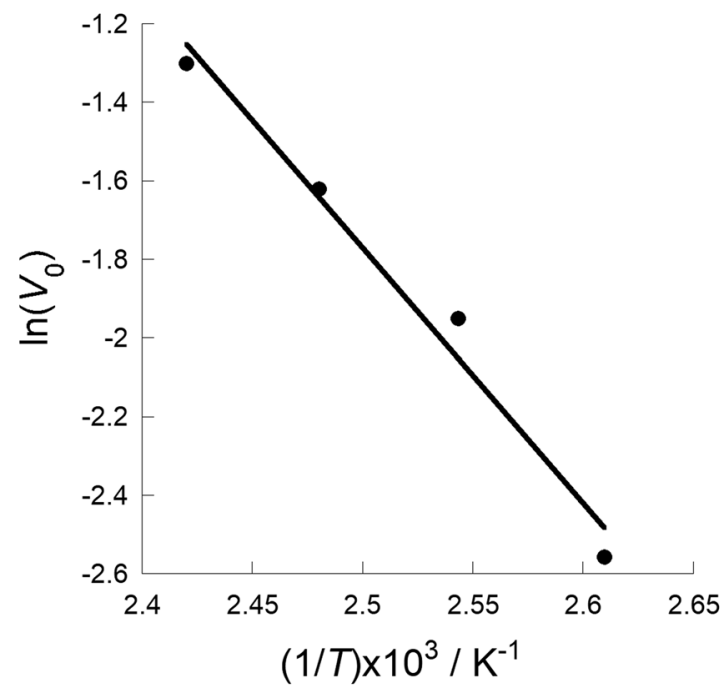

Figure 7. Arrhenius plot for urea synthesis from ammonium carbamate catalyzed by DBU.

energy for the synthesis of urea using DBU as the catalyst was found to be $54.1 \mathrm{~kJ} \mathrm{~mol}^{-1}$. This value is lower than that of urea synthesis from $\mathrm{NH}_{3}$ and $\mathrm{CO}_{2}$ under high pressure $\left(94.5 \mathrm{~kJ} \mathrm{~mol}^{-1}\right)^{43}$. Recovered environmental ammonia (ammonia carbamate) and DBU showed the possibility for low energy input urea synthesis.

\section{Discussion}

Based on the NMR and FT-IR results, we propose that DBU is protonated by ammonium carbamate through counter-cation exchange, which weakens the carbamate $\mathrm{C}=\mathrm{O}$ bond and increases its electrophilicity. The proposed reaction mechanism based on our results is shown in Fig. 8.

At first, DBU undergoes cation exchange with ammonium carbamate to form the DBU salt of carbamate and ammonia. The formed ammonia then nucleophilically attacks the weakened carbonyl group of the carbamate anion, after which urea is formed by dehydration and DBU is regenerated.

Results of solvent effect experiment (Fig. 3) support the proposed reaction mechanism. In the proposed reaction mechanism, molecular ammonia is required to nucleophilically attack the carbonyl group. Therefore, the solubility of ammonia in the solvent may play a key role since the organic base catalyst is dissolved in the reaction solvent.

In summary, we successfully synthesized urea from ammonium carbamate using DBU as an organic base catalyst. In particular, the best yield of $35 \%$ was achieved in DMSO as the solvent at $100^{\circ} \mathrm{C}$. The reaction was applicable to other ammonium salts, such as ammonium carbonate and ammonium bicarbonate. NMR and FT-IR spectroscopies reveal that DBU undergoes cation exchange with ammonium carbamate; the activated $\mathrm{C}=\mathrm{O}$ group of the exchanged salt then undergoes nucleophilic attack by ammonia. Despite the reaction rate with DBU being low, this new catalytic system has the potential to change how environmental ammonia is treated for a sustainable society. 


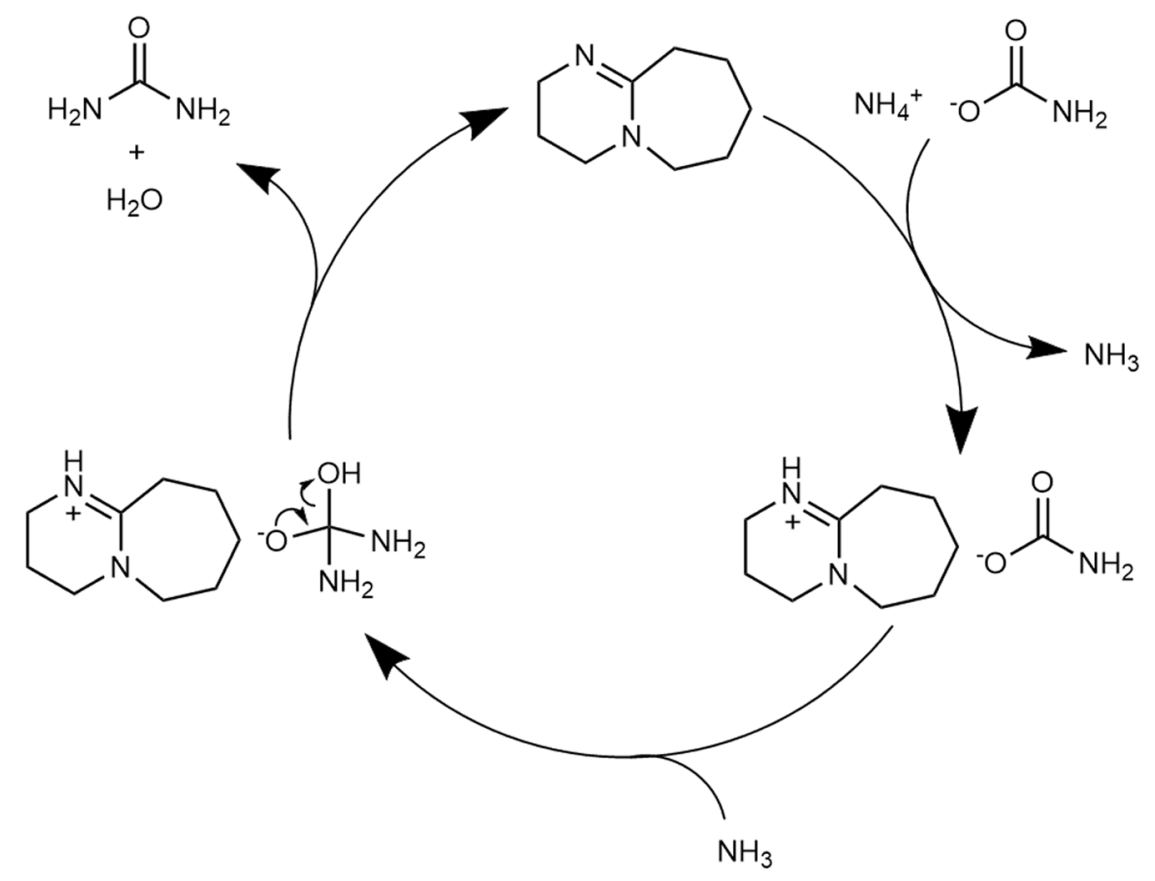

Figure 8. Proposed mechanisms for the DBU catalyzed urea-synthesis reaction from ammonium carbamate.

\begin{abstract}
Methods
General. Proton nuclear magnetic resonance ( ${ }^{1} \mathrm{H}$ NMR) spectra were recorded on an AVANCE III HD $400 \mathrm{MHz}$ NMR spectrometer (Bruker) or an AVANCE III HD $500 \mathrm{MHz}$ NMR spectrometer (Bruker). Carbon-13 nuclear magnetic resonance $\left({ }^{13} \mathrm{C}\right.$ NMR) spectra were recorded on the AVANCE III HD $400 \mathrm{MHz}$ NMR spectrometer with a Cryoprobe (Bruker). Mass spectra were recorded on a solariX Fourier transform ion cyclotron resonance mass spectrometer (Bruker) or a ACQUITY UPLC system (Waters) or a GCMS-QP2010 SE gas chromatograph mass spectrometer (Shimadzu). Fourier transform infrared (FT-IR) spectra were recorded on a IRTracer-100 Fourier transform infrared spectrophotometer (Shimadzu). UV/Vis spectra were acquired on a UV-2600 UV-Vis spectrophotometer (Shimadzu). The pressure in the pressure tight vessel was measured using a Krone digital pressure gauge KDM30 (Krone).
\end{abstract}

Chemicals. 1,8-Diazabicyclo[5.4.0]undec-7-ene (DBU), 1,5-diazabicyclo[4.3.0]non-5-ene (DBN), 1,5,7-triazabicyclo[4.4.0] dec-5-ene (TBD), 7-methyl-1,5,7-triazabicyclo[4.4.0]dec-5-ene (MTBD), 1,1,3,3-tetramethylguanidine (TMG), triethylamine $\left(\mathrm{Et}_{3} \mathrm{~N}\right)$ and ammonium carbamate, were purchased from Tokyo Chemical Industry Co., Ltd. 4-dimethylaminopyridine (DMAP), 1,4-diazabicyclo[2.2.2] octane (DABCO), ammonium carbonate, ammonium bicarbonate, urea were purchased from FUJIFILM Wako Pure Chemical Corporation. 1,8-bis(dimethylamino)naphthalene (proton sponge) was purchased from Sigma-Aldrich Japan. All solvents used were of anhydrous grade, and all chemicals were used as received without further purification.

Urea synthesis reaction. In a typical reaction, ammonium carbamate ( $3.8 \mathrm{mmol}, 1$ eq. $)$ and base $(0.38 \mathrm{mmol}, 0.1$ eq. $)$ were placed in a $20-\mathrm{mL}$ stainless-steel autoclave (TAIATSU Techno) with $1 \mathrm{~mL}$ of solvent. The autoclave was set in an oil bath at the desired temperature and the contents were stirred. The pressure inside the autoclave increased to $0.5 \mathrm{MPa}$ during heating due to the $\mathrm{NH}_{3}$ and $\mathrm{CO}_{2}$ generated by the thermal decomposition of ammonium carbamate inside the vessel. At the required time, the autoclave was immediately quenched by immersion in an ice bath.

When ammonia gas and $\mathrm{CO}_{2}$ were used as substrates, an inner cylinder with an open top was used. The base $(0.38 \mathrm{mmol}, 0.1$ eq.) was placed in the inner cylinder with $1 \mathrm{~mL}$ of solvent, and ammonium carbamate $(3.8 \mathrm{mmol}$, 1 eq.) was placed in the space between the outside of the inner cylinder and the inside of the outer cylinder. The ammonium carbamate located exterior to the catalyst decomposed to generate gaseous ammonia and $\mathrm{CO}_{2}$.

Urea detection. The urea-synthesis reaction solution was analyzed by GC-MS to qualitatively determine the amount of urea produced. In addition, the concentration of urea was quantitatively determined by the Fearon reaction ${ }^{44}$. For the Fearon reaction, $28.4 \%$ aqueous phosphoric acid and $0.4 \mathrm{M}$ aqueous diacetyl monoxime were prepared in deionized water. A $690-\mu \mathrm{L}$ aliquot of the phosphoric acid solution, $300 \mu \mathrm{L}$ of the diacetyl monoxime solution, and $10 \mu \mathrm{L}$ of the sample were placed in a $1.5 \mathrm{~mL}$ microtube with a lid-lock. The tube was shaken well for $10 \mathrm{~s}$ and then heat at $90^{\circ} \mathrm{C}$ for $60 \mathrm{~min}$ with slow shaking. As the required time, the tube was immediately quenched by immersion in liquid nitrogen. The reacted solution was subjected to UV/Vis spectroscopy in the 200-800 nm range, and the urea concentration was determined using the calibration curve technique. 
Received: 13 September 2019; Accepted: 4 February 2020;

Published online: 18 February 2020

\section{References}

1. Ahn, Y.-H. Sustainable nitrogen elimination biotechnologies: A review. Prosess Biochem. 41, 1709-1721 (2006).

2. Hooda, P. S., Edwards, A. C., Anderson, H. A. \& Miller, A. A review of water quality concerns in livestock farming areas. Sci. Total Environ. 250, 143-167 (2000).

3. Amon, B., Amon, T., Boxberger, J. \& Alt, C. Emissions of NH3, N2O and CH4 from dairy cows housed in a farmyard manure tying stall (housing, manure storage, manure spreading). Nutr. Cycl. Agroecosys. 60, 103-113 (2001).

4. Bluteau, C. V., Massé, D. I. \& Leduc, R. Ammonia emission rates from dairy livestock buildings in Eastern Canada. Biosyst. Eng. 103, 480-488 (2009).

5. Horn, H. H. V., Wilkie, A. C., Powers, W. J. \& Nordsted, R. A. Components of Dairy Manure Management Systems. J. Dairy Sci. 77, 2008-2030 (1994).

6. Vries, M. \& Boer, I. J. M. Comparing environmental impacts for livestock products: A review of life cycle assessments. Livest. Sci. 128, 1-3 (2010).

7. Hristov, A. et al. Ammonia emissions from dairy farms and beef feedlots. Can. J. Anim. Sci. 91, 1-35 (2011).

8. Behera, S. N., Sharma, M., Aneja, M. \& Balasubramanian, R. Ammonia in the atmosphere: a review on emission sources, atmospheric chemistry and deposition on terrestrial bodies. Environ. Sci. Pollut. Res. 20, 8092-9131 (2013).

9. Fowler, D. et al. The global nitrogen cycle in the twenty-first century. Phil. Trans. R. Soc. B 368, (2013).

10. Tchobanoglous, G., Burton, F. L. \& Stensel, H. D. Wastewater Engineering: Treatment and Reuse 4th edition, (Metcalf and Eddy Inc., 2002).

11. Hong, Z., Hanaki, K. \& Matsuno, T. Greenhouse Gas - N2O Production during Denitrification in Wastewater Treatment. Water Sci. Technol. 28, 203-207 (1993).

12. Czepiel, P., Crill, P. \& Harriss, R. Nitrous Oxide Emissions from Municipal Wastewater Treatment. Environ. Sci. Technol. 29, 2352-2356 (1995).

13. Clemens, J. \& Haas, B. Nitrous Oxide Emissions in Sewer Systems. Acta Hydrochim. Hydrobiol. 25, 96-99 (1997).

14. Law, Y., Ye, L., Pan, Y. \& Yuan, Z. Nitrous oxide emissions from wastewater treatment processes. Phil. Trans. R. Soc. B 367, 1265-1277 (2012).

15. O’Farrell, T. P., Frauson, F. P., Cassel, A. F. \& Bishop, D. F. Nitrogen removal by ammonia stripping. J. Water Pollut. Control. Fed. 44, $1527-1535$ (1972).

16. Saracco, G. \& Genon, G. High temperature ammonia stripping and recovery from process liquid waters. J. Hazard. Mater. 37, 191-206 (1994).

17. Provolo, G. et al. Nitrogen removal from digested slurries using a simplified ammonia stripping technique. Waste Manage. 69, 154-161 (2017)

18. Bernal, M. P. \& Lopez-Real, J. M. Natural zeolites and sepiolite as ammonium and ammonia adsorbent materials. Bioresour. Technol. 43, 27-33 (1993).

19. Liu, C. Y. \& Aika, K. Ammonia Adsorption on Ion Exchanged Y-zeolites as Ammonia Storage Material. J. Jpn. Petro. Inst. 46, 301-307 (2003).

20. Chou, L.-H., Tsai, R.-I., Chang, J.-R. \& Lee, M. T. Regenerable adsorbent for removing ammonia evolved from anaerobic reaction of animal urine. J. Environ. Sci. 18, 1176-1181 (2006).

21. Wang, S. \& Peng, Y. Natural zeolites as effective adsorbents in water and wastewater treatment. Chem. Eng. J. 156, 11-24 (2010).

22. Erdey, L., Gal, S. \& Liptay, G. Thermoanalytical properties of analytical-grade reagents: Ammonium salts. Talanta 11, 913-940 (1964).

23. Haynes, R. J. \& Naidu, R. Influence of lime, fertilizer and manure application on soil organic matter content and soil physical conditions: A review. Nutr. Cycl. Agroecosys. 51, 123-137 (1998).

24. Stevens, M. P. Polymer Chemistry 3rd edition, (Oxford university press, 1999).

25. Salamone, J. C. Polymeric Materials Volume11, (CRC press, 1996).

26. Rollinson, A. N., Jones, J., Dupont, V. \& Twigg, M. V. Urea as a hydrogen carrier: a perspective on its potential for safe, sustainable and long-term energy supply. Energy Environ. Sci. 4, 1216-1244 (2011).

27. Lan, R., Irvine, J. T. S. \& Tao, S. Ammonia and related chemicals as potential indirect hydrogen storage materials. Int. J. Hydrogen Energy 37, 1482-1494 (2012).

28. Krase, N. W. \& Gaddy, V. L. Synthesis of urea from ammonia and carbon dioxide. Ind. Eng. Chem. Res. 14, 611-615 (1922).

29. Kawasumi, S. Equilibrium of the CO2-NH3-Urea-H2O System under High Temperature and Pressure. III. Effect of Water Added on Liquid-Vapor Equilibrium. Bull. Chem. Soc. Jpn. 26, 218-222 (1952).

30. Meessen, J. Urea synthesis. Chem. Ing. Tech. 86, 2180-2189 (2014).

31. Worrell, E., Phylipsen, D., Einstein, D. \& Martin, N. Technical Report: Energy use and energy intensity of the U.S. chemical industry, (Lawrence Berkeley National Lab., 2000).

32. Barzagli, F., Mani, F. \& Peruzzini, M. From greenhouse gas to feedstock: formation of ammonium carbamate from CO2 and NH3 in organic solvents and its catalytic conversion into urea under mild conditions. Green Chem. 13, 1267-1274 (2011).

33. Barzagli, F., Mani, F. \& Peruzzini, M. Carbon dioxide uptake as ammonia and amine carbamates and their efficient conversion into urea and 1,3-disubstituted ureas. J. CO2 Util. 13, 81-89 (2016).

34. Kaljurand, I. et al. Extension of the Self-Consistent Spectrophotometric Basicity Scale in Acetonitrile to a Full Span of 28 pKa Units: Unification of Different Basicity Scales. J. Org. Chem. 70, 1019-1028 (2005).

35. Kaupmees, K., Trummal, A. \& Leito, I. Basicities of Strong Bases in Water: A Computational Study. Croat. Chem. Acta. 87, 385-395 (2014).

36. Gennaro, A., Isse, A. A. \& Vianello, E. Solubility and electrochemical determination of CO2 in some dipolar aprotic solvents. J. Electroanal. Chem. interfacial electrochem. 289, 203-215 (1990).

37. Crovetto, R. Evaluation of Solubility Data of the System CO2-H2O from $273 \mathrm{~K}$ to the Critical Point of Water. J. Phys. Chem. Ref. Date 20, 575-589 (1991).

38. Carroll, J. J., Slupsky, J. D. \& Mather, A. E. The Solubility of Carbon Dioxide in Water at Low Pressure. J. Phys. Chem. Ref. Date 20, 1201 (1991).

39. Prini, R. F. \& Crovetto, R. Evaluation of Date on Solubility of Simple Apolar Gases in Light and Heavy Water at High Temperature. J. Phys. Chem. Ref. Date 18, 1231-1243 (1989).

40. Cota, I., Chimentao, R., Sueiras, J. \& Medina, F. The DBU-H2O complex as a new catalyst for aldol condensation reactions. Catal. Commun. 9, 2090-2094 (2008).

41. Heldebrant, D. J., Jessop, P. G., Thomas, C. A., Eckert, C. A. \& Liotta, C. L. The Reaction of 1,8-Diazabicyclo[5.4.0]undec-7-ene (DBU) with Carbon Dioxide. J. Org. Chem. 70, 5335-5338 (2005).

42. Carafa, M., Mesto, E. \& Quaranta, E. DBU-Promoted Nucleophilic Activation of Carbonic Acid Diesters. Eur. J. Org. Chem. 2458-2465 (2011).

43. Zhang, X., Zhang, S., Yao, P. \& Yuan, Y. Modeling and simulation of high-pressure urea synthesis loop. Comput. Chem. Eng. 29, 983-992 (2005)

44. Fearon, E. R. The carbamido diacetyl reaction: a test for citrulline. Biochem. J. 33, 902-907 (1939). 


\section{Acknowledgements}

This work was carried out by the joint usage/research program of the Artificial Photosynthesis, Osaka City University.

\section{Author contributions}

Y.M. wrote the main manuscript text. Y.M. and K.M. planned the experiments. Y.N. helped the experiments. All authors contributed to project discussion and approved the final manuscript.

\section{Competing interests}

The authors declare no competing interests.

\section{Additional information}

Supplementary information is available for this paper at https://doi.org/10.1038/s41598-020-59795-6.

Correspondence and requests for materials should be addressed to Y.M.

Reprints and permissions information is available at www.nature.com/reprints.

Publisher's note Springer Nature remains neutral with regard to jurisdictional claims in published maps and institutional affiliations.

(i) Open Access This article is licensed under a Creative Commons Attribution 4.0 International License, which permits use, sharing, adaptation, distribution and reproduction in any medium or format, as long as you give appropriate credit to the original author(s) and the source, provide a link to the Creative Commons license, and indicate if changes were made. The images or other third party material in this article are included in the article's Creative Commons license, unless indicated otherwise in a credit line to the material. If material is not included in the article's Creative Commons license and your intended use is not permitted by statutory regulation or exceeds the permitted use, you will need to obtain permission directly from the copyright holder. To view a copy of this license, visit http://creativecommons.org/licenses/by/4.0/.

(C) The Author(s) 2020 